\title{
Restoration and Purification of Dissolved Organic Nitrogen by Bacteria and Phytoremediation in Shallow Eutrophic Lakes Sediments
}

\author{
Xin Li and Yi Yue \\ Laboratory of Waterway Environmental Protection Technology, Tianjin Water Transport Engineering Science Research Institute, Tianjin \\ 300456, China
}

\begin{abstract}
Endogenous organic nitrogen loadings in lake sediments have increased with human activity in recent decades. A 6-month field study from two disparate shallow eutrophic lakes could partly reveal these issues by analysing seasonal variations of biodegradation and phytoremediation in the sediment. This paper describes the relationship between oxidation reduction potential, temperature, microbial activity and phytoremediation in nitrogen cycling by calculation degradative index of dissolved organic nitrogen and amino acid decomposition. The index was being positive in winter and negative in summer while closely positive correlated with biodegradation. Our analysis revealed that rather than anoxic condition, biomass is the primary factor to dissolved organic nitrogen distribution and decomposition. Some major amino acids statistics also confirm the above view. The comparisons of organic nitrogen and amino acid in abundance and seasons in situ provides that demonstrated plants cue important for nitrogen removal by their roots adsorption and immobilization. In conclusion, enhanced microbial activity and phytoremediation with the seasons will reduce the endogenous nitrogen loadings by the coupled mineralization and diagenetic process.
\end{abstract}

\section{Introduction}

In recent years, the global problems of lakeeutrophication, especially nitrogen distribution or migration, have been greatly concerned due to their wide spreading. This issue is critical in understanding the mechanism of nitrogen cycling and freshwater ecosystem responses to anthropogenic mediated change. Sediments are the main destinations as storing pool of nutrients by diagenetic transformation while some endogenous organic nitrogen release into the sediment leading to a eutrophic restoration under some conditions. In addition to mostly studied exogenous inputting, conversely, some cases had focused mainly in form, content, distribution and seasonal variation of dissolved organic nitrogen (DON) degradation and migration; and others in situ, including the profile of amino acids and its cycle by realizing the comparisons in mineralization, degradation and diagenesis in sediments[1-2].

In some specific cases, eutrophic lake is hot due to its widely encountered. In sediment-water interface, the occurrence and decomposition of DON is accurate understanding by geochemical dynamics as well as some related impact factors. The mineralization of degradation and phytoremediation was unclearly in calculation and interrelation. The redox potential (Eh) in sediment is closely related with hypoxia condition. Besides Eh, the seasonality of temperature and microbial activity are another factors. Likewise, phytoremediation is also a research point in sediments restoration. All these mutual relations have many uncertainties to further cognition yet.

To illustrate the issue, the mainly part of dissolved organic nitrogen, amino acids degradation could be explained by specific calculation [3]. The current laboratory incubation was to estimate this process under the assumption which the statics analyse in situ is less and the cycling mode proved to be studied by theoretical formula [4]. These incubations suggest that bacterial and photochemical degradation play a critical role in the composition of DON in some suitable conditions [5]. Because the total hydrolysable amino acid (THAA) in situ frequently comprises the largest part of DON in sediments and they are the nutrition sources to heterotrophs [6]. In this paper, our aim was to determine whether the remove or inhibit of endogenous DON cycling by factors of temperature, Eh, microbial activity (fluorescein-diacetate-ester, 'FDA' to represent) and phytoremediation to control eutrophic restoration. A further aim was to provide a powerful tool to study the sources and biogeochemical cycling of labile organic nutrient in aquatic system.

\section{Material and Methods}

\subsection{Sample Collection}

\footnotetext{
* Corresponding author Yi Yue: lixin1609@tju.edu.cn
} 
Samples were obtained from Lake Qingnian (latitude $39^{\circ} 06^{\prime} 38^{\prime} \prime \mathrm{N}$, longitude $117^{\circ} 06^{\prime} 59^{\prime}$, E) and Lagoon Qilihai (latitude $39^{\circ} 17^{\prime} 21^{\prime}$ ' $\mathrm{N}$, longitude $117^{\circ} 35^{\prime} 32^{\prime}$ ' E) in Tianjin. Qingnian Lake is a typical shallow urban eutrophic lake that had no large stationary sources of pollution, whilst the lake is subject to discharges by sewage in previous years. Lagoon Qilihai was evolved by a process of marine regression at the late Holocene in North China Plain which is a marsh wetland with agriculture and fisheries features. In field study, we monitored depth, temperature, $\mathrm{pH}$, turbidity, chlorophyll- a of overlying water and moisture content, Eh of sediment. The results in situ were showed in Table. 1. Samples of Lake Qingnian were obtained from two contrasting spots named 'QNP' and 'QNC' while Lagoon Qilihai had only one sampling spots named 'QLH'. 'QNP' is a zone which has luxuriant plant near the edge of bay and ' $\mathrm{QNC}$ ' is a deep open zone at central east of the lake. Every sample was mixing five cores by standardized method collected from the surface sediments $(10 \mathrm{~cm}$ depth) by a self-made cylindrical core sampler. Sediment and water samples were removed in polypropylene bags or acid-washed PE bottles back to the laboratory. Within $12 \mathrm{~h}$ after sample collection, the pore water was obtained by the centrifugal drainage technique [7]. The sediment samples were tiled to dry and sieved by 60 meshes. And then it stored in the refrigerator.

Table 1 Values of depth, temperature, $\mathrm{pH}$, turbidity, chl- $\alpha$, and moisture content in field study.

\begin{tabular}{|c|c|c|c|c|c|c|}
\hline $\begin{array}{c}\text { Cor } \\
\mathrm{e}\end{array}$ & $\begin{array}{c}\text { Dept } \\
\mathrm{h} \\
(\mathrm{m})\end{array}$ & $\begin{array}{l}\mathrm{T} \\
\left({ }^{\circ}\right. \\
\mathrm{C})\end{array}$ & $\mathrm{pH}$ & $\begin{array}{c}\text { Moistur } \\
\mathrm{e} \\
\text { content } \\
(\%)\end{array}$ & $\begin{array}{c}\text { Turbidi } \\
\text { ty } \\
\text { (NTU) }\end{array}$ & $\begin{array}{c}\text { Chlorop } \\
\text { hyll- } \alpha \\
(\mu \mathrm{g} / \mathrm{L})\end{array}$ \\
\hline $\begin{array}{c}\text { QN } \\
\text { P }\end{array}$ & 1.7 & $\begin{array}{c}23 . \\
8\end{array}$ & 8.4 & $55-64$ & $61-73$ & 63.9 \\
\hline $\begin{array}{c}\text { QN } \\
\text { C }\end{array}$ & 3.9 & $\begin{array}{c}23 . \\
8\end{array}$ & 8.4 & $61-72$ & $55-70$ & 23.1 \\
\hline $\begin{array}{c}\text { QL } \\
\mathrm{H}\end{array}$ & $\begin{array}{l}4.2- \\
4.8 \\
\end{array}$ & $\begin{array}{c}23 . \\
4 \\
\end{array}$ & 8.2 & $50-59$ & $42-53$ & 15.3 \\
\hline
\end{tabular}

\subsection{Sample Extraction and Analysis}

Dissolved inorganic nitrogen (ammonium, nitrate and nitrite) and urea were determined calorimetrically by UV-2800 ultraviolet spectrophotometer (Unico, China) [8]. Total dissolved nitrogen (TDN) in water was determined by the method of Persulfate Oxidation (PO) while its concentration in sediment was monitored by Kjedahl method. DON was calculated as a margin between the TDN and DIN (NH4+-N, NO3--N and

Table 2 Average contents of TDN, DON, THAA-N, Urea-N and Hexosamine-N in two lakes. (mg/Kg).

\begin{tabular}{cccccccccc}
\hline & \multicolumn{1}{c}{ Overlying Water } & \multicolumn{3}{c}{ Pore Water } & & \multicolumn{2}{c}{ Sediments } \\
& & & & & & & \\
& & & & & & & \\
& QNP and QNC & QLH & QNP & QNC & QLH & QNP & QNC & QLH \\
\hline TDN & 6.10 & 8.87 & 14.42 & 17.81 & 10.42 & 4641 & 5053 & 1562 \\
DON & 3.85 & 4.60 & 8.38 & 8.92 & 5.43 & 4020 & 4483 & 1355 \\
THAA-N & 1.88 & 1.61 & 3.79 & 3.98 & 2.50 & 1569 & 1777 & 579 \\
\hline
\end{tabular}

NO2--N) readings. Chlorophyll- a was determined calorimetrically by Jin and Tu' method [9]. The Eh was monitored by the national standardized method (SL941996) by a platinum electrode. The THAA and hexamine (amino sugar) was determined by CEC chromatography and ninhydrin-postcolumn derivation [10]. And they were monitored by amino acid analyser (Hitachi L-8900, Japan) after sample filtration. The FDA value was monitored in this method: the surface sediment samples were cultured after pre-treatment; after adding FDA and centrifugation, cores were determined colorimetrically at $490 \mathrm{~nm}$ using the external standard method [11].

\section{Results and Discussion}

\subsection{Nitrogen Components in Two Lakes}

To investigate the mechanism behind, we first monitor each component of nitrogen in water and sediment. The average concentrations of five objects in 6-month experiments were observed in Tab. 2. The TDN of Lake Qingnian was characterized $5053 \mathrm{mg} / \mathrm{Kg}$ and 4483 $\mathrm{mg} / \mathrm{Kg}$ in average in sediment. Meanwhile, the DON were $4641 \mathrm{mg} / \mathrm{Kg}$ and $4020 \mathrm{mg} / \mathrm{Kg}$ respectively while significantly higher than theirs in overlying water and in pore water. Comparing with inorganic nitrogen, DON represented the dominant nitrogen pool, being about $90 \%$ and $55 \%$ of TDN in sediment and overlying water respectively. Lagoon Qlihai had a less severe eutrophication condition and 'QNP' had a less eutrophication condition than 'QNC'. It once again proved that phytoremediation can be a method of lakes eutrophication. Meanwhile, the TDN/DON ratios in two lakes were similar to other cases. All above revealed that sediments are the main nitrogen pool due to the internal release and Lake Qingnian had a severe nitrogen loading than Lagoon Qilihai. In terms of DON, THAA-N (Nitrogen in THAA) was the main component in sediment and in pore water while urea and hexamine slightly accounting some of weights. These phenomena may be explained by the dynamics of nitrogen release: DON was ammoniated to $\mathrm{NH} 4+$ and some amino acids being decomposition in this process. An anaerobic condition that contributed to amino acids biodegradation by the production of its own and hexamine was derived from microbial decomposition. Besides, external input had lead urea concentration higher in overlying water than in pore water. 


\begin{tabular}{ccccccccc}
\hline Urea-N & 0.83 & 0.89 & 0.53 & 0.58 & 0.96 & 1.46 & 2.20 & 2.31 \\
Hexosamine-N & -- & -- & 0.55 & 0.61 & 0.46 & 145 & 163 & 77
\end{tabular}

The average contents of TDN, DON and THAA-N in 'QNP' were lower than 'QNC'. It is suggested that plant root and microbial activity promote organic nitrogen convert to inorganic via ammonification, especially in reed and ceratophyllum prosperity. Being more nitrogen in sediment, an enhanced internal loading leads to a higher DON concentration in Lake Qingnian than Lagoon Qilihai. Meanwhile, it could be explained a more activated microbial status and a principle which heterotrophs in sediments is prosperity by more ON sources.

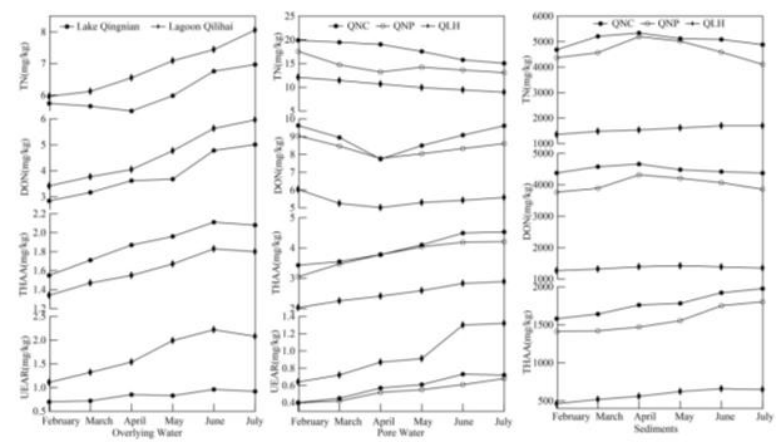

Fig 1 Seasonal dynamics of TN, DON, THAA and urea in two lakes in 6-month field study.

Seasonal dynamics for TDN, DON, THAA and hexamine measured were given in Fig. 1. It depicted that Lake Qingnian and Lagoon Qilihai have similar trends. In Lake Qingnian, 'QNP' had greater seasonal amplitude than 'QNC'. After April, TDN and DON decreased gradually in sediment while their contents had an opposite trend in overlying water. Comparing with DON concentration in pore water and overlying water, there were no regular gradient differences between them. The external input of DON may be the main reason to explain these phenomena. The THAA values in three phases had similar increasing trends. It showed that urea inputting make great affect to its content especially in 'QLH'. Referring DON and THAA values in Lagoon Qilihai were higher than Lake Qingnian may be due to exogenous inputs. The seasonal variability of urea was increased in pore water also confirmed the above process.

\subsection{Degradative Index of Amino Acid in Sediment-Water Interface}

The recognition of degradative index (DI) of amino acid in organic nitrogen cycling allows conclusions to be drawn to the mineralization and biodegradation in the sediment-water interface. The index is an indicator of organic matter diagenesis. DI was calculated with a formula based on principal components analysis. It is a diversity of samples ranging from fresh phytoplankton to highly degraded turbidity sediment samples:

$$
D I=\sum_{i}\left[\frac{\operatorname{var}_{i}-A V G \operatorname{var}_{i}}{S T D \operatorname{var}_{i}}\right] \times \text { fac.Coe. } f_{i}
$$

Where DI is the degradation index; vari is the individual amino acids (mole percentage); AVG vari and STD vari are the mean, standard deviation respectively. The fac.Coe.fi is the factor coefficient by Dauwe's experienced projection from Tab. 3 (2). The more negative for DI value is the more degraded condition for the sample. And a positive DI value indicatives fresh materials in sediment. Correlation analysis was performed using a Spearman Rank Correlation coefficient. Statistically significant differences between the two lakes were determined using the 'Execl Statistical Package'. Means are reported with a 95\% confidence interval. DI values in two lakes measured are given in Fig. 2 respectively. Alanine, threonine, aspartate, glycine and glutamic acid take larger weight for DI. They are also closely related to the biomass and oxygen condition in sediment. Despite the large percentage of arginine and lysine, it is because they are more nitrogen molecules amino acids. DI ranged from 1.99 to -1.77 with an apparent downward trend. That means amino acid had an apparent accelerated degradation tendency in sediment. The downward rate of Lagoon Qilihai was more significant. It fully illustrated that, with less artificial interference, the lake has a more effective selfpurification capacity by biodegradation and phytoremediation. Meanwhile, the 'QNP' had a higher degradability than the 'QNC'. A reasonable explanation to above phenomena: Expansion of plant root, microbial activity and the loose surface sediment with new coverage of organism leading to an increasing tendency of sediment porosity and further strengthens the fluxes values calculably. Furthermore, it suggested that the seasonable change of phytoremediation is another main related factor to amino acid accumulation or degradation in sediments.

Table 3 Mean deviation, standard deviation and factor coefficient for different amino acids in two lakes.

\begin{tabular}{|c|c|c|c|c|c|c|c|}
\hline & \multicolumn{2}{|c|}{$\begin{array}{c}\text { Plant Area in } \\
\text { Lake } \\
\text { Qingnian }\end{array}$} & \multicolumn{2}{|c|}{$\begin{array}{c}\text { Centre Area } \\
\text { in Lake } \\
\text { Qingnia }\end{array}$} & \multicolumn{2}{|c|}{$\begin{array}{l}\text { Lagoon } \\
\text { Qilihai }\end{array}$} & \multirow[b]{2}{*}{$\begin{array}{c}\text { Fac.Coe.f } \\
\mathrm{i}\end{array}$} \\
\hline & $\begin{array}{c}\mathrm{AVG} \\
\operatorname{var}_{\mathrm{i}}\end{array}$ & $\begin{array}{c}\mathrm{ST} \\
\mathrm{D} \\
\operatorname{var}_{\mathrm{i}}\end{array}$ & $\begin{array}{c}\mathrm{AVG} \\
\operatorname{var}_{\mathrm{i}}\end{array}$ & $\begin{array}{c}\mathrm{ST} \\
\mathrm{D} \\
\operatorname{var}_{\mathrm{i}}\end{array}$ & $\begin{array}{c}\text { AVG } \\
\operatorname{var}_{i}\end{array}$ & $\begin{array}{c}\mathrm{ST} \\
\mathrm{D} \\
\operatorname{var}_{\mathrm{i}}\end{array}$ & \\
\hline ASP & 7.59 & 2.5 & 8.62 & 2.6 & 5.44 & 2.2 & -0.102 \\
\hline GLU & 8.50 & 2.4 & 8.89 & 2.4 & 8.79 & 2.4 & 0.065 \\
\hline HIS & 2.53 & 0.4 & 2.61 & 0.4 & 2.12 & 0.3 & 0.158 \\
\hline SER & 6.00 & 2.4 & 6.32 & 2.5 & 5.71 & 2.3 & 0.015 \\
\hline ARG & 12.53 & 0.3 & $\begin{array}{c}11.5 \\
3\end{array}$ & 0.4 & $\begin{array}{c}14.4 \\
9\end{array}$ & 0.6 & -0.115 \\
\hline GLY & 10.62 & 2.1 & $\begin{array}{c}10.8 \\
4\end{array}$ & 2.3 & $\begin{array}{c}11.2 \\
5\end{array}$ & 2.5 & -0.099 \\
\hline THR & 7.26 & 1.0 & 6.65 & 0.8 & 8.72 & 1.1 & -0.129 \\
\hline ALA & 7.76 & 1.3 & 7.70 & 1.3 & 8.72 & 1.4 & -0.043 \\
\hline TYR & 2.00 & 1.1 & 1.86 & 1.1 & 1.76 & 1.1 & 0.178 \\
\hline CYS & 0.72 & 0.1 & 1.03 & 0.1 & $\begin{array}{c}0.07 \\
8\end{array}$ & 0.1 & 0.203 \\
\hline PRO & 4.15 & 0.7 & 5.04 & 0.9 & 1.77 & 0.2 & 0.099 \\
\hline MET & 1.55 & 1.0 & 1.10 & 1.0 & 1.37 & 1.0 & 0.134 \\
\hline VAL & 6.01 & 1.7 & 5.44 & 1.6 & 6.45 & 1.8 & -0.044 \\
\hline PHE & 3.60 & 0.6 & 3.39 & 0.5 & 4.16 & 0.6 & 0.134 \\
\hline ILE & 3.45 & 0.5 & 3.35 & 0.5 & 3.73 & 0.5 & 0.139 \\
\hline LEU & 6.46 & 1.6 & 6.33 & 1.6 & 6.87 & 1.7 & 0.169 \\
\hline LYS & 9.26 & 2.1 & 9.61 & 2.0 & 8.69 & 1.9 & -0.086 \\
\hline
\end{tabular}




\subsection{Correlations between DI and Related Factors}

To determine the biodegradation mechanism with related factors, we monitored three relevant ones as the known parameters. The correlation between DI and related factors can reflect the ammonification, nitrification and denitrification in the lake. Seasonality of Eh, temperature and microbial activity (FDA to represent) were shown in Tab. 4. These three factors have a similar trend which their contents are lower in winter and higher in summer. In Eh value, there was an obvious difference between two lakes after May while its value was no more than $200 \mathrm{mV}$ rendering a reduction condition apparently. Contents of Eh and FDA in 'QNP' were slightly higher than 'QNC' in the same month. These suggested that photosynthesis was more susceptible and root parasitic in shallow water caused more microbial activity.

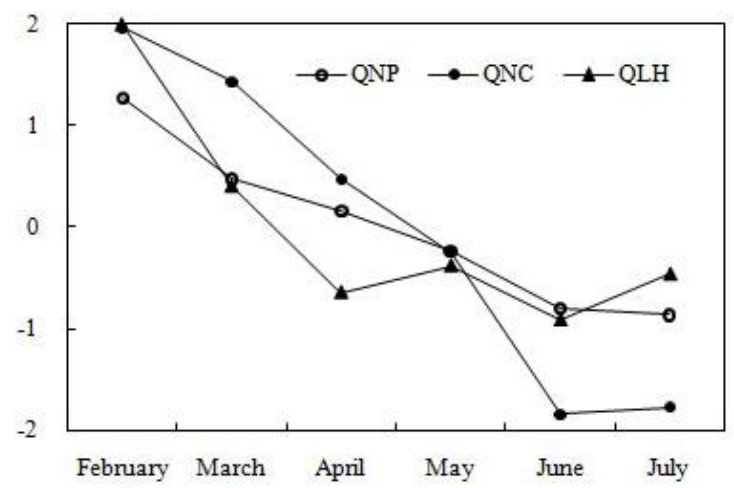

Fig 2 Seasonal dynamics of degradative index (DI) in two lakes in 6-month field study.

FDA had a positive correlation with THAA in two lakes indicating that aerobic bacteria adapts significantly to more oxygen and takes the majority in surface sediments. Greater seasonal fluctuations of glycine and glutamic acid in sediment can reflected this phenomenon. Glycine is the simplest amino acid and the primary product of metabolism for aerobic microorganisms in utility of sugar fermentation. Glutamate is the main structure amino acids and the intermediate products for aerobic metabolism. Thus, these positive coefficients reflected specific importance of microbial activity and sediment oxygen condition and hence other electron acceptors in surface sediments. From Tab. 4, correlation between three factors and DI in Lake Qingnian is different. That may revealed that out of the three related factors, phytoremediation plays is an important role in nutrient cycling because of plant utility of nutrients and its extended roots.

Table 4 Seasonal dynamics of Eh, temperature and FDA and their correlation to DI in two lakes.

\begin{tabular}{cccccccccc}
\hline & \multicolumn{3}{c}{ FDA $(\mu \mathrm{mol} / \mathrm{g})$} & \multicolumn{3}{c}{ Eh $(\mathrm{mv})$} & \multicolumn{3}{c}{ Temperature $\left({ }^{\circ} \mathrm{C}\right)$} \\
& QNP & QNC & QLH & QNP & QNC & QLH & QNP & QNC & QLH \\
\hline Feb. & 0.38 & 0.36 & 0.77 & 52 & 46 & 32 & 4.1 & 4.1 & 2.3 \\
Mar. & 0.48 & 0.46 & 0.86 & 90 & 82 & 55 & 6.9 & 6.9 & 5.9 \\
Apr. & 0.68 & 0.62 & 0.97 & 102 & 99 & 62 & 13.2 & 13.2 & 11.2 \\
May & 0.86 & 0.81 & 1.01 & 121 & 115 & 87 & 21 & 21 & 20.4 \\
June & 0.94 & 0.88 & 1.08 & 148 & 107 & 110 & 24.4 & 24.4 & 22.9 \\
July & 0.91 & 0.88 & 1.02 & 136 & 103 & 114 & 27.9 & 27.9 & 26.9 \\
Coe. f0.8749 & 0.9494 & 0.9723 & 0.8689 & 0.76760 .98130 .9397 & 0.9720 & 0.9777 \\
\hline
\end{tabular}

FDA and DI had an obvious negative correlation ( $\mathrm{R}>0.95$ in two lakes respectively). It indicated that biodegradation is prone react to the diagenesis. Meanwhile, it is reported that the activity of amination bacteria is increased with rising temperature in nature condition shown that temperature and DI had an obvious negative correlation in Lake Qingnian $(\mathrm{R}>0.95)$, but not in Lagoon Qilihai $(\mathrm{R}=0.77)$. The same condition carried out between Eh and $\mathrm{DI}(\mathrm{R} \approx 0.8$ in two lakes). Therefore, we can conclude that microbial activity in sediment is more important in these three factors for mineralization and diagenetic process. Changes of alanine, threonine and aspartate in the two lakes can be an explanation to the condition. Aspartate and alanine are synthetic materials for plant, microbial metabolism. Less in Lagoon Qilihai reflected greater biological activity there directly. And more threonine in Lagoon Qilihai revealed agriculture and fisheries are its major environmental factors. Because of threonine is the main component for feed additive. This conclusion is consistent with other studies. And the above all may be explained by the following reason: Although the redox potential and temperature have different situations, there always had some corresponding microbial which can still complete the degradation process for organic matter. The correlation parameters between DI and three factors for Lake Qingnian are greater than Lagoon Qilihai. It indicated that more oxygen, microbes and increasing temperature can promote the diagenesis in urban lake.

\section{Conclusions}

In the shallow eutrophic Lake Qingnian and Lagoon Qilihai, internal nitrogen release was significantly greater than the general level in sediment-water interface where DON takes the main contribution. The factors of microbes, Eh and temperature could affect the nitrogen releasing, degradation and diagenesis under oxidation conditions in lake sediment. Plants prosperity and microbial activity can relieve the hypoxia condition to inhibit biodegradation while temperature rising makes an exacerbation. And plant roots extension makes more loosed sediments could improve the oxygen conditions. In conclusion, endogenous organic nitrogen biodegrade accelerated in summer by the factors of temperature, phytoremediation and microbial conditions. Meanwhile, it can be quantitative decrypted the inhibition or promotion expressed by the form of DI and by their liner correlation. The activity of microorganisms in the sediments was primary factor than oxygen status or temperature. Seasonal variations for some amino acid indirectly confirmed this phenomenon. So that amino acid in mineralization and degradation is an important aspect to lakes ecological restoration.

\section{Acknowledgements}

This work was supported by "Study of foreign soil water retention, prevent salinization, heavy metal soil remediation, soil backfill and ecological restoration technique in land reclamation. (TKS150218). 


\section{References}

1 A.D., T., G.E., M., and M.F., F. (2007) Distributions, cycling and recovery of amino acids in estuarine waters and sediments, Environmental Chemistry Letter 5,7 .

2 Duan, S., and Bianchi, T. S. (2007) Particulate and dissolved amino acids in the lower Mississippi and Pearl Rivers (USA), Marine Chemistry 107, 16.

3 Lomstein, B. A., Jørgensen, B. B., Schubert, C. J., and Niggemann, J. (2006) Amino acid biogeo- and stereochemistry in coastal Chilean sediments, Geochimica et Cosmochimica Acta 70, 20.

4 Dauwe, B., and Middelburg, J. J. (1998) Amino acids and hexosamines as indicators of organic matter degradation state in North Sea sediments, Limnology \& Oceanography 43, 17.

5 Sattayatewa, C., Pagilla, K., Pitt, P., Selock, K., and Bruton, T. (2009) Organic nitrogen transformations in a 4-stage Bardenpho nitrogen removal plant and bioavailability/biodegradability of effluent DON, water research 43, 10 .

6 Tappin, A. D., Millward, G. E., and Fitzsimons, M. F. (2007) Distributions, cycling and recovery of amino acids in estuarine waters and sediments, Environ Chem Lett 5, 7.

7 Jones, D. L., Shannon, D., Murphy, D. V., and Farrar, J. (2004) Role of dissolved organic nitrogen (DON) in soil $\mathrm{N}$ cycling in grassland soils, Soil Biology \& Biochemistry 36, 8.

8 Badr, E.-S. A., Tappin, A. D., and Achterberg, E. P. (2008) Distributions and seasonal variability of dissolved organic nitrogen in two estuaries in SW England, Mar Chem 110, 12.

9 Jin, X. C., and Tu, Q. Y., (Eds.) (2000) Rules for investigation of lake eutrophication, China Environmental Science Press, Bei jing.

10 Jones, D. L., Shannon, D., Junvee-Fortune, T., and Farrar, J. F. (2005) Plant capture of free amino acids is maximized under high soil amino acid concentrations, Soil Biology \& Biochemistry 37, 3.

11 Chong, J. C., and Fan, C. X. (2010) Environmental effect of sediment dredging in lake:IV.influences of dredging on microbial activity and functional diversity of microbial community in sediments and its significance, Journal of Lake Sciences 22, 8. 